\title{
Establish Registry of Cerebral Palsy in Qalubia Goveronrate
}

\author{
GEHAN EL-MENIAWY, Ph.D*; RANIA GALAL AL-DEEN, Ph.D.* and YASMEIN N. MOHAMMED, M.Sc.** \\ The Department of Physical Therapy for Pediatrics, Faculty of Physical Therapy, Cairo University* and \\ Shibin El-Kanater General Hospital**, Egypt
}

\begin{abstract}
Background: Patient registry is"an organized system that uses observational study methods to collect uniform data (clinical and other) to evaluate specified outcomes for a population defined by a particular disease, condition, or exposure, and that serves a predetermined scientific, clinical, or policy purpose(s).
\end{abstract}

Aim of Study: To establish registry of Cerebral Palsy (CP) in Qalubia governorate.

Subjects and Methods: Children with CP who are receiving physical therapy services of both genders, ranged in age from 2 months to 18 years in govermental hospitals, Health insurance hospitals and private physical therapy centers which deal with children in Qalubia governorate. The number of cases which included in this study was 181 cases. The outcomes measures were Viking speech Scale, Manual Ability Classification System (MACS), Gross Motor Function Classification System (GMFCS) and Gross Motor Function Measure (GMFM).

Results: One hundred and eighty one cases were enrolled with a prevalence of 6 per 100.000 live births. The participants in the study, spastic CP was the most common type representing, $84.60 \%$ of the total sample, while Hypotonic was $13.20 \%$, Ataxic was $1.7 \%$ and Dyskinetik was $0.60 \%$. Percentage of CP based on GMFCS were $1.20 \%$ for level I, $21.50 \%$ for level II, $12.70 \%$ for level III, $9.90 \%$ for level IV, and $54.70 \%$ for level V. GMFM was used to determine the score of performance for each participant. According to MACS and Viking speech scale high incidences of children with $\mathrm{CP}$ were classified at level IV.

Conclusion: The current study revealed that prevalence of CP in Qalubia governorate was 181 children representing 6 per 100.000 live births. The spastic type $84.60 \%$ was the most common while the ataxic type $1.7 \%$ is the least prevalence. Demography revealed $51.9 \%$ of children wereboys and $48.1 \%$ were girls, high incidence of children with CP level V using GMFCS, and level IV using MACS and Viking speech scale.

Key Words: Qalubia-Cerebral palsy-Registry-Physical therapy.

Correspondence to: Dr. Gehan El-Meniawy, The Department of Physical Therapy for Pediatrics, Faculty of Physical Therapy, Cairo University, Egypt

\section{Introduction}

PATIENT registries have been defined as "an organized system that uses observational study methods to collect uniform data (clinical and other) to evaluate specified outcomes for a population defined by a particular disease, condition, or exposure, and that serves a predetermined scientific, clinical, or policy purpose(s) [1].

In brief, a patient registry is a collectionfor one or more purposes of standardized information about a group of patients who share a condition or experience. The use of "patient" in patient registries is often used to distinguish the focus of the data set on health information. Currently, there is no consistent definition of the term "patient registry" used in the health research field. Terms such as clinical registries, clinical data registries, disease registries, and outcomes registries are also used to describe the same data collection method [2]

Registers of CP are defined as "population [based] databases issuing from multiple sources, relying on a clear definition and inclusion and exclusion criteria of $\mathrm{CP}$, and requiring a mix of skills with the collaboration of obstetricians, pediatricians, and epidemiologists" [3].

Cerebral Palsy (CP) is the most common severe motor disability in children, and its severity is demonstrated by the fact that $40 \%$ of children with the condition cannot walk independently, $[4,5]$ onethird have epilepsy, [6] up to one-third are nonverbal, $[7,8]$ and about one-half have some degree of cognitive impairment [5,9-11]

Cerebral palsy comprises a group of permanent disorders of the development of movement and posture, causing activity limitation, that are attributed to non-progressive disturbances that occur in 
the developing fetal or infant brain. The motor disorders of cerebral palsy are often accompanied by disturbances of sensation, perception, cognition, communication, and behavior; by epilepsy; and by secondary musculoskeletal problems [12]

The onset of CP occurs very early in life, and although it is described as a non-progressive disorder, research over the past several years has highlighted a number of health conditions and functional declines experienced by individuals with $\mathrm{CP}$ as they age [13]

Registers of CP are defined as "population [based] databases issuing from multiple sources, relying on a clear definition and inclusion and exclusion criteria of $\mathrm{CP}$, and requiring a mix of skills with the collaboration of obstetricians, pediatricians, and epidemiologists [4]

\section{Subjects and Methods}

\section{Subjects:}

181 cases of $\mathrm{CP}$ children of both gender from Qalubia City and its village (Baha, Tokh, Qahah, Shobra, Shibin El-Kanter, El-Khanka) participated in this studytheir ages ranged from 2 month to 18 years. Children with CP were selected from governmental hospitals, health insurance hospitals, university hospitals and private physical therapy centers which deal with children in Qalubia governorate. This study continues up-to six months from ${ }^{1 \mathrm{st}}$ of February up to 31 August 2018. They were subjected to confidential registry form.

\section{Methods:}

1- The Gross Motor Function Classification System (GMFCS): The GMFCS describes the functional characteristics of $\mathrm{CP}$ patients in five levels, from I to $\mathrm{V}$, level I being the mildest in the following age groups: Up to 2yrs. 2-4yrs., 4-6 years and between 6 to 12 years. For each level, separate descriptions are provided. Children in level III usually require orthoses and assisting mobility devices, while children in level II do not require assisting mobility devices after age 4 . Children in level III sit independently, have independent floor mobility, and walk with assisting mobility devices. In level IV, affected children function in supported sitting but independent mobility is very limited. Children in level V lack independence even in basic antigravity postural control and need power mobility [14]

2- Gross Motor Functional Measurement (GMFM): It is a standardized observational instrument designed and validated to measure change in gross motor function over time in children with cerebral palsy. The GMFM consists of 88 items grouped into 5 dimensions: 1- Lying and rolling (17 items), 2- Sitting (20 items), 3-Crawling and kneeling (14 items), 4- Standing (13 items) and 5- Walking, running and jumping (24 items) all items generally could be completed by age 5 years in children without motor delay. The scoring is recorded by percentage [15].

3- Manual Ability Classification System for Children with Cerebral Palsy (4-18) years is a functional description that can be used in a way that is complement to the diagnosis of cerebral palsy and its subtypes [16]

4- The Viking Speech Scale is developed for use with children aged 4 years and above, the scale has four levels [17].

\section{Procedure:}

Consent form was taken from children's parents. Approval litter from the Faculty of Physical Therapy, Cairo University to start this research was obtained.

Data collected from 1- Birth information of each child obtained from parents or medical reports. 2- Examination of CP children. Time of data collection for each case ranged one and half hour up to two hours for each case divided from 2 up to 3 sessions.

\section{Results}

Total number of children under age of 18 years old was 2, 701, $716(48 \%)$ of total study (target population for this study) according to 2017 cencus. The number of $\mathrm{CP}$ sampled cases who $\mathrm{CP}$ patient was 181 representing about 6 per 100,000 live births, their ages ranged from 2 months to 17 years old.

Analysis was done based on a chi-square test for the relationship between $\mathrm{CP}$ prevalence and main sample characteristics. A 95\% confidence interval for GMFM score was computed. The collected data were statistically processed and analyzed using the Statistical Package for Social Sciences (SPSS V-20).

\section{Characters of the study sample:}

\section{1-Place of residence:}

Results of the study showed that the place of residence for all the children, was $(44.8 \%)$ from children lived in Rural areas and (55.20\%) from children lived in Urban areas. 


\section{2- General medical information:}

As shown in Table (2) (11.6\%) from mothers had multiple birth while the percentage $(88.4 \%)$ represent mother's hadn't multiple births. According to type of delivery intervention about (38.7\%) was normal labor and $(61.3 \%)$ was cesarean section. Furthermore, $(2.2 \%)$ of mothers had zero previous birth, (22.1\%) had one previous birth, (32.6\%) had two previous birth and about $(43.1 \%)$ had more than three previous births. Regarding giving the delivery by who there was about $(98.3 \%)$ by obstruction and $(1.7 \%)$ midwife. As shown at (Table 2 ) about $(24.3 \%)$ from mother's had complication during pregnancy and $(75.7 \%)$ hadn't complications during pregnancy. About (80.1\%) from mother's didn't take any medications during pregnancy while $(19.9 \%)$ took medications during pregnancy. For the gestational age this study showed that about $(79.5 \%)$ of children were full term babies, while $(17.7 \%)$ were preterm babies and about $(2.8 \%)$ were post term gestational age. This study also shows that about (11.6\%) of mothers had multiple birth and (76.2\%) of this multiple birth was twins and $(23.5 \%)$ was triplet, finally location of delivery was $(98.3 \%)$ at hospital and $(1.7 \%)$ at home.

\section{3- Children characteristics:}

Regarding the age of children there were (64.1\%) from children their age ranged from (14) years, (32\%) from (4-10) years, $(1.1 \%)$ from $(10-15)$ years and $(2.8 \%)$ from (0-1) years. Also, children sex was represented by $(51.9 \%)$ male and (48.1\%) female. And children weight from (5-10) $\mathrm{kg}$ represented by (18.8\%), from (10-15) kg, represented by (51.4\%), from (15-20) $\mathrm{kg}$ represented by $(24.3 \%)$ and above $20 \mathrm{~kg}$ represented by $(2.2 \%)$.

About birth order for children it was represented by $(9.9 \%)$ for 1 st birth order, $(23.2 \%)$ for 2 nd birth order, $(32.1 \%)$ for 3 rd birth order, $(23.2 \%)$ for 4 th birth order and $(11.6 \%)$ for more than 4 birth order.

According to birth defects and known syndromes, about (72.4\%) of children hadn't any birth defect, $(27.6 \%)$ had birth defect, $(88.4 \%)$ hadn't any known syndromes and only $(11.6 \%)$ had known syndrome.

Regarding weight at time of delivery (55.2\%) of the children had normal birth weight (2500$4200) \mathrm{gm},(42 \%)$ had low birth weight $(<1500 \mathrm{gm})$, $(0.6 \%)$ had very low birth weight $(<1000 \mathrm{gm})$ and finally $(2.2 \%)$ had high birth weight (more than 4200gm).

On the other hand, onset of CP presented on this study shows that $(16 \%)$ had perinatal causes
(77.9\%) had postnatal causes and $(6.1 \%)$ had prenatal causes.

\section{4- Associated disorders:}

As show at (Table 4) associated disorders with cerebral palsy $(40.3 \%)$ of children affected with epilepsy, (59.7\%) not affected with epilepsy. Concerning the intellectual disorders (63\%) affected, (37\%) not affected. Concerning the visual disorder (35.4\%) affected, $(64.6 \%)$ not affected. Concerning the hearing disorder (14.9\%) affected and $(85.1 \%)$ not affected. Regarding the speech disorder $(81.8 \%)$ affected, (18.2\%) not affected. concerning swallowing disorder (35.4\%) affected and (64.6\%) not affected by swallowing disorders.

\section{5- Cerebral palsy subtypes:}

$(49.7 \%)$ of children had spastic diplegia, (23.8\%) had spastic quadriplegia, (7.2\%) had spastic hemiplegia right side, $(2.8 \%)$ spastic hemiplegia left side, $(1.1 \%)$ had dystonia, $(0.6 \%)$ had athetosis, $(1.7 \%)$ had ataxia, $(12.1 \%)$ had hypotonia as show at (Table 5).

\section{6- Gross motor function classification system:}

Table (6) show that (1.2\%) of children were at level I gross motor function classification system GMFCS, $(21.5 \%)$ of children were at level at II GMFCS, (12.7\%) were at level III of GMFCS, $(9.9 \%)$ were at level IV of GMFCS and $(54.7 \%)$ were at level V of GMFCS.

\section{A- Motor function levels: \\ B- Total GMFM Score:}

As shown in (Table 7) total GMFM scores have a mean of 95.87 and standard deviation of 70.93 (95.87 \pm 70.93 ) for which $95 \%$ confidence interval for the CP population of Qalubia can be estimated by $(70.93 \pm 10.54)$, which means in $95 \%$ of the cases children in Qalubia governorate with CP expected to have a GMFM Score between (60.39) and (81.39).

\section{7- Manual ability:}

Table (8) show that (14.9\%) of children at level I manual ability classification system MACS, $(19.3 \%)$ at level II MACS, $(22.1 \%)$ at level III MACS, (26\%) at level IVMACS, (17.7\%) at level V MACS.

\section{8- Viking speech scale:}

Table (9) show that $(8.3 \%)$ of children were at level I Viking scale, (17.7\%) were at level II viking scale, $(34.8 \%)$ were at level III viking scale, $(39.2 \%)$ were at level IV viking. 
Table (1): Place of residence of cerebral palsy children in Qalubia Governorate.

\begin{tabular}{lccc}
\hline Variable & Freq. & $\%$ & Rank \\
\hline Urban & 100 & 55.2 & 1 \\
Rural & 81 & 44.8 & 2 \\
\hline Total & 181 & 100 & - \\
\hline
\end{tabular}

Table (2): General medical information concerning participants.

\begin{tabular}{lccc}
\hline Variable & Freq. & $\%$ & Rank \\
\hline Complication during pregnancy: & & & \\
Yes & 44 & 24.3 & 1 \\
No & 137 & 75.7 & 2 \\
\hline Total & 181 & 100 & -
\end{tabular}

Medications during pregnancy:

\begin{tabular}{llll} 
Yes & 36 & 19.9 & 1 \\
No & 145 & 80.1 & 2 \\
\hline Total & 181 & 100 & -
\end{tabular}

Gestational age:

Preterm $<37$ week

Full term 37-42 week

Post term $<42$ week

\begin{tabular}{llll} 
Post term <42 week & 5 & 2.8 & 3 \\
\hline Total & 181 & 100 & - \\
Number of previous births: & & & \\
$\quad$ Zero & 4 & 2.2 & 4 \\
$\quad$ One & 40 & 22.1 & 3 \\
$\quad$ Two & 59 & 32.6 & 2 \\
Three + & 78 & 43.1 & 1 \\
\hline$\quad$ Total & 181 & 100 & - \\
Multiple births: & & & \\
$\quad$ Yes & 21 & 11.6 & 2 \\
No & 160 & 88.4 & 1 \\
\hline Total & 181 & 100 & -
\end{tabular}

Multiple births, if yes:

\begin{tabular}{llll} 
Twins & 16 & 76.2 & 1 \\
Triplet & 5 & 23.8 & 2 \\
\hline Total & 21 & 100 & - \\
\hline Giving delivery by. & & &
\end{tabular}

Giving delivery by:

\begin{tabular}{llll} 
Obstruction & 178 & 98.3 & 1 \\
Midwife & 3 & 1.7 & 2 \\
\hline Total & 181 & 100 & -
\end{tabular}

Location of delivery:

\begin{tabular}{llll} 
Home & 3 & 1.7 & 2 \\
Hospital & 178 & 98.3 & 1 \\
\hline Total & 150 & 100 & -
\end{tabular}

Delivery intervention:

\begin{tabular}{llll} 
Normal & 70 & 38.7 & 2 \\
Cesarean & 111 & 61.3 & 1 \\
\hline Total & 181 & 100 & - \\
\hline
\end{tabular}

Table (3): Children characteristics.

\begin{tabular}{|c|c|c|c|}
\hline Variable & Freq. & $\%$ & Rank \\
\hline \multicolumn{4}{|l|}{ Child age: } \\
\hline From 0-1 year & 5 & 2.8 & 3 \\
\hline From 1-4 years & 116 & 64.1 & 1 \\
\hline From 4-10 years & 58 & 32 & 2 \\
\hline From $10-15$ years & 2 & 1.1 & 4 \\
\hline Total & 181 & 100 & - \\
\hline \multicolumn{4}{|l|}{ Child sex: } \\
\hline Male & 94 & 51.9 & 1 \\
\hline Female & 87 & 48.1 & 2 \\
\hline Total & 181 & 100 & - \\
\hline \multicolumn{4}{|l|}{ Child weight: } \\
\hline Less than $5 \mathrm{~kg}$ & 6 & 3.3 & 4 \\
\hline From $5-10 \mathrm{~kg}$ & 34 & 18.8 & 3 \\
\hline From $10-15 \mathrm{~kg}$ & 93 & 51.4 & 1 \\
\hline From $15-20 \mathrm{~kg}$ & 44 & 24.3 & 2 \\
\hline More than $20 \mathrm{~kg}$ & 4 & 2.2 & 5 \\
\hline Total & 181 & 100 & - \\
\hline \multicolumn{4}{|l|}{ Child birth order: } \\
\hline $1^{\text {st }}$ & 18 & 9.9 & 5 \\
\hline $2 \mathrm{nd}$ & 42 & 23.2 & 2 \\
\hline $3 \mathrm{rd}$ & 58 & 32.1 & 1 \\
\hline $4^{\text {th }}$ & 42 & 23.2 & 2 \\
\hline More & 21 & 11.6 & 4 \\
\hline Total & 181 & 100 & - \\
\hline \multicolumn{4}{|l|}{ Onset of cerebral palsy: } \\
\hline Prenatal & 11 & 6.1 & 3 \\
\hline Perinatal & 29 & 16 & 2 \\
\hline Postnatal & 141 & 77.9 & 1 \\
\hline Total & 181 & 100 & - \\
\hline \multicolumn{4}{|l|}{ Were any birth defects present? } \\
\hline Yes & 50 & 27.6 & 2 \\
\hline No & 131 & 72.4 & 1 \\
\hline Total & 181 & 100 & - \\
\hline \multicolumn{4}{|l|}{ Is there a known syndrome? } \\
\hline Yes & 21 & 11.6 & 2 \\
\hline No & 160 & 88.4 & 1 \\
\hline Total & 181 & 100 & - \\
\hline \multicolumn{4}{|l|}{ Weight at delivery } \\
\hline Very low birth of weight $<4-1000 \mathrm{gm}$ & 1 & 0.6 & 4 \\
\hline low birth of weight $<1500 \mathrm{gm}$ & 76 & 42 & 2 \\
\hline Normal birth of weight $2500-4200 \mathrm{gm}$ & 100 & 55.2 & 1 \\
\hline High birth of weight $>4200 \mathrm{gm}$ & 4 & 2.2 & 3 \\
\hline Total & 181 & 100 & - \\
\hline
\end{tabular}


Table (4): Frequency and percentage of associated disorders with cerebral palsy cases.

\begin{tabular}{|c|c|c|c|}
\hline Variable & Freq. & $\%$ & Rank \\
\hline \multicolumn{4}{|l|}{ Epilepsy: } \\
\hline Affected & 73 & 40.3 & 2 \\
\hline Not affected & 108 & 59.7 & 1 \\
\hline Total & 181 & 100 & - \\
\hline \multicolumn{4}{|l|}{ Intellectual: } \\
\hline Affected & 114 & 63 & 1 \\
\hline Not affected & 67 & 37 & 2 \\
\hline Total & 181 & 100 & - \\
\hline \multicolumn{4}{|c|}{ Visual (by following object): } \\
\hline Affected & 64 & 35.4 & 2 \\
\hline Not affected & 117 & 64.6 & 1 \\
\hline Total & 181 & 100 & - \\
\hline \multicolumn{4}{|c|}{ Hearing (by following sounds): } \\
\hline Affected & 27 & 14.9 & 2 \\
\hline Not affected & 154 & 85.1 & 1 \\
\hline Total & 181 & 100 & - \\
\hline \multicolumn{4}{|l|}{ Speech: } \\
\hline Affected & 148 & 81.8 & 1 \\
\hline Not affected & 33 & 18.2 & 2 \\
\hline Total & 181 & 100 & - \\
\hline \multicolumn{4}{|c|}{ Swallowing (according to age): } \\
\hline Affected & 64 & 35.4 & 2 \\
\hline Not affected & 117 & 64.6 & 1 \\
\hline Total & 181 & 100 & - \\
\hline
\end{tabular}

Table (5): Distribution of participants according to topography and motor type.

\begin{tabular}{lccc}
\hline Variable & Freq. & $\%$ & Rank \\
\hline Quadriplegia & 43 & 23.8 & 2 \\
Diplegia & 90 & 49.7 & 1 \\
Triplegia & 2 & 1.1 & 7 \\
Right hemiplegia & 13 & 7.2 & 4 \\
Left hemiplegia & 5 & 2.8 & 5 \\
Mainly athetosis & 1 & 0.6 & 9 \\
Mainly dystonia & 2 & 1.1 & 7 \\
Ataxia & 3 & 1.7 & 6 \\
Hypotonia & 22 & 12.1 & 3 \\
\hline Total & 181 & 100 & - \\
\hline
\end{tabular}

Table (6): Frequency and percentage of each GMFCS level of the participants.

\begin{tabular}{lccc}
\hline Variable & Freq. & $\%$ & Rank \\
\hline Level I & 2 & 1.2 & 5 \\
Level II & 39 & 21.5 & 2 \\
Level III & 23 & 12.7 & 3 \\
Level IV & 18 & 9.9 & 4 \\
Level V & 99 & 54.7 & 1 \\
\hline Total & 181 & 100 & - \\
\hline
\end{tabular}

Table (7): Total GMFM score of the participants.

\begin{tabular}{lccc}
\hline Variable & Freq. & $\%$ & Rank \\
\hline Less 115 & 109 & 60.2 & 1 \\
From 115-160 & 37 & 20.5 & 2 \\
From 161-200 & 16 & 8.8 & 4 \\
More than 200 & 19 & 10.5 & 3 \\
\hline Total & 181 & 100 & - \\
Mean $\quad=95.87$ & & & \\
Std. deviation $=70.93$ & & & \\
\hline
\end{tabular}

Table (8): Frequency and percentage of impairment of each MACS level.

\begin{tabular}{lccc}
\hline Variable & Freq. & $\%$ & Rank \\
\hline Level I & 27 & 14.9 & 5 \\
Level II & 35 & 19.3 & 3 \\
Level III & 40 & 22.1 & 2 \\
Level IV & 47 & 26 & 1 \\
Level V & 32 & 17.7 & 4 \\
\hline Total & 181 & 100 & - \\
\hline
\end{tabular}

Table (9): Viking scale.

\begin{tabular}{lccc}
\hline Variable & Freq. & $\%$ & Rank \\
\hline Level I & 15 & 8.3 & 4 \\
Level II & 32 & 17.7 & 3 \\
Level III & 63 & 34.8 & 2 \\
Level IV & 71 & 39.2 & 1 \\
\hline Total & 181 & 100 & - \\
\hline
\end{tabular}

\section{Discussion}

There is no CP registry in Qalubia governorate, so the current study was conducted to establish data base about CP children who are receiving physical therapy services in governmental hospitals, university hospitals, insurance hospital and physical therapy privet centers, in addition to those who aren't receiving physical therapy services in Qalubia governorate. All children were diagnosed as $\mathrm{CP}$ included in this study. Latest information about population Qalubia in 1/1/2017 total population was $(5,627,420)$. Persons are 18 years or less $(2$, 701, 716).

Regarding demogaphic classification of $\mathrm{CP}$, the collected data in this study revealed that $\mathrm{CP}$ affects both genders. However, male were affected more than female 94 of 181 patients were male (51.9\%) and 87 of 181 patients were female (48.1\%). Consistent with the results of Johnson [18] who reported that boy/girl ratio in Europe is 1.33/1, and Laisram et al., [19] who reported the boy/girl ratio is $1.9 / 1$ in India. 
Regarding area, the current study shows that $\mathrm{CP}$ cases in urban more than $\mathrm{CP}$ cases in rural as 100 cases represent $55.20 \%$ in urban, and 81 cases $44.80 \%$ in rural, agree with El-Tallawy et al., [20] reported that $\mathrm{CP}$ cases in urban more than rural as 32 cases $(61.5 \%)$ in urban and 20 cases $(38.5 \%)$ in rural, disagree with Abd El-Aziem and Morsy, [22] reported that 162 cases $(81 \%)$ in rural and 38 cases $(19 \%)$ urban.

Regarding the gestational age, full term delivery represented the highest frequency with percentage $79.5 \%$. This matched the opinion of Dag Moster, et al., [21] who found that, compared with delivery at 40 weeks' gestation, delivery at 37 or 38 weeks or at 42 weeks or later was associated with an increased risk of CP. This result of study is not matched the opinion of with Oskoui et al., [22] who reported that, $\mathrm{CP}$ is commonly reported in children who were born before 28 weeks of gestation. Similarly, Cans et al., [23] concluded that, the prevalence of CP decreases significantly with increasing gestational age category: $14.6 \%$ at $22-27$ weeks' gestation, $6.2 \%$ at $28-31$ weeks, $0.7 \%$ at $32-36$ weeks, and $0.1 \%$ in term infants.

Regarding birth weight, children born with very low birth weight represented $0.60 \%$ and with low birth weight represented $42.00 \%$ while the result of normal birth weight represented $55.00 \%$ and high birth weight represented $2.20 \%$. It comes in agreement with Jonas H. Ellenberg, Karin B. Nelson, [24] who reported Low birth weight and short gestation were important risk factors for $\mathrm{CP}$, but these characteristics were uncommon, and the majority of children with $\mathrm{CP}$ were of normal birth weight and term gestational age. The result of this study is not matched the opinion of Platt et al., [25]; Cans et al., [26] who reported that, the highest prevalence of $\mathrm{CP}$ is among children whose birth weight is from 1000 to 1499 grams $(\mathrm{g})$ while the lowest prevalence is in children who were born over $2500 \mathrm{~g}$.

Regarding to type of delivery for CP Children, 111 were delivered by cesarean section $(61.30 \%)$ and 70 were represented by spontaneous normal delivery (38.70\%). Regarding to this result CP children who delivered by emergency cesarean section were very high due to, low economic status, they do many trials for normal labor, as the majority of CP children from rural and lack of neonatal care so emergency cesarean section was done for live saving either to the mother or infant. There were misunderstandings that elective caesarean section could decrease rate of $\mathrm{CP}$.
Regarding type of $\mathrm{CP}$, the current study showed spastic CP was the most common type representing, $84.60 \%$ of the total sample. While Hypotonic was $13.20 \%$, Ataxic was $1.7 \%$ and Dyskinetik was $1.7 \%$. These findings come in agreement with Rosenbaum et al., [27] ; Blair, [28] and Parkinson et al., [29] who stated that, spastic CP is the most common type of CP. Spasticity is the predominant type of $\mathrm{CP}$, occurring in $77 \%$ to $93 \%$ of $\mathrm{CP}$ cases, dyskinesia ranges from $2 \%$ to $15 \%$, and ataxia ranges from $2 \%$ to $8 \%$. Similarly, Stanley et al., [30] stated that, spastic CP is the most prevalent of overall types, occurring in upwards of $70 \%$ of all cases.

Regarding CP subtypes, the results also showed that, diplegic type showed the highest frequency representing $49.70 \%$, while quadriplegic represented $23.80 \%$ and hemilplegic represented $10 \%$. The results confirmed the findings of Belonwu RO, et al., [31] ; Himmelman K., et al., [32] they stated that, rates of spastic $\mathrm{CP}$ in these studies varied between $70 \%$ and $90 \%$.

In the current study hypotonic $\mathrm{CP}$ cases represent $13.20 \%$, it is agree with Abd El-Aziem and Morsy, [21] who reported that highly percentage of hypotonic type due to mixed with ataxia if persistent hypotonia and may be transfer to other type especially spastic type if it is transient, persistent or transient according to child age as under 3 years considered transient.

Spastic diplegic CP is the most predominant subtype representing $49.70 \%$, of all CP cases in this study. This could be attributed to the fact that infants born prematurely and low birth weight has a heightened risk of devolpingdiplegic $\mathrm{CP}$ as these babies are prone to oxygen problems during birth. Cerbral palsyguide.com, [33]. This is also matched the opinion of Ashwal et al., [34] and Tong-Wai et al., [35] reported that, spastic diplegia is one of the most common clinical subtypes of $\mathrm{CP}$ regardless of birth weight and gestation.

The result of study showed CP quadriplegia $23.80 \%$ which is ranked as second highest type of $\mathrm{CP}$ cases. This is not matched the opinion of Himmelmann K, et al., [32] ; Normark E, et al., [36] and Howard J, et al., [37] they reported that the proportion of children with quadriplegic CP (15\%) was lower than reported in one the study from Australia $(32 \%)$, whether it was higher than two study in Western Sweden (6\% and 10\% respectively). The result of current study is matched the opinion of Hamdy N. El-Tallawy, et al., [20] they reported the proportion of children with quadriplegic $\mathrm{CP}$ in 
their study $(42.3 \%)$ was higher than that reported in study carried out in Norway (14.9\%).

Ataxic and Dyskinetik CP children in our study are representing the lowest percentage which $(1.7 \%$ and $0.60 \%$ respectively), this is matched the opinion of El-Tallawy et al., [38] recorded that ataxic CP ratio was $3.9 \%$. Ataxic $\mathrm{CP}$ is clinically observed in approximately $5-10 \%$ of all cases of $\mathrm{CP}$, making it the least frequent form of $\mathrm{CP}$ diagnosed McHale et al., [39]

Regarding type of evaluation, the current study revealed that the children's GMFCS was $1.20 \%$ at level I, $21.50 \%$ at level II, $12.70 \%$ at level III, $9.90 \%$ at level IV, and $54.70 \%$ at level V. Our results are in disagreement with Beckung et al., [40] who reported who reported that, over $60 \%$ of children with CP could walk without assistive walking devices (GMFCS levels I-II). This also comes in Himmelmann et al., [41] and Lowing et al., [42] reported that all five levels within the GMFCS-E \& R were represented where of $22 \%$ children were classified in GMFCS-E \& R I, 26\% in GMFCS-E \& R II, $16 \%$ in GMFCS-E \& R III, $17 \%$ in GMFCS-E \& R IV and 19\% of the children were classified in GMFCS-E \& R V. The results of current study is in agreement with Hesham S. Darwesh, et al., [43] who reported level of impairment according to gross motor function classification system: Level of impairment according to gross motor function classification system, level, I $6(2.6 \%)$, level II, 28 (12.3\%), level III, 58 (25.4\%), level IV, 42 (18.4\%), level V, 94 (41.2\%).

Regarding assoiated impairment $\mathrm{CP}$, this study showed that $40.30 \%$ of CP children had Epilepsy. Intellectual problems founded $35.40 \%$, visual disorder in $35.40 \%$, hearing disorder in $14.90 \%$, speech disorder in $81.80 \%$ and swallowing disorder in $35.40 \%$. This comes in agreement with Jan, [44] who found that, children with CP suffer from multiple problems and potential disabilities such as mental retardation, epilepsy, feeding difficulties, ophthalmologic and hearing impairments. More over these findings were supported by Novak et al., [45] who reported that, children with $\mathrm{CP}$ have a wide range of associated disabilities, including intellectual disability, hearing and visual deficits, nutritional and feeding problems, respiratory infections and epilepsy.

Regarding prevelanve of $\mathrm{CP}$, the current study revealed that the total CP cases in Qalubia governorate were 181 cases representing 6 per 100,000 live births, although physiotherapy often constitutes a major part of the team approach in rehabilitation of CP. Prevalence of CP occurs at rate 2-2.5 per 1000 live births in developed countries (Shevell and Bodensteiner, [46]. Also in Egypt the prevelance was 1.2 per 1000 live births in Imbaba North Giza (HeshamS. Darwesh, et al., [43]

\section{Conclusion:}

The current study revealed that children with CP were 181 representing 6 per 100.000 live birth have been receiving physical therapy; incidence of spastic type was major while ataxic was the least prevalence. Demography was $51.9 \%$ male and $48.1 \%$ female, high incidence of children with CP level V in GMFCS, level IV in MACS and Viking speech scale.

Prevalence of CP based on GMFCS were; $1.20 \%$ for level I, $21.50 \%$ for level II, $12.70 \%$ for level III, $9.90 \%$ for level IV, and $54.70 \%$ for level $\mathrm{V}$, while prevalence of recruited children based on MACS were; $14.90 \%$ for level I, $19.30 \%$ for level II, $22.10 \%$ for level III, $26.00 \%$ for level IV, and $17.70 \%$ for level V. Viking speech scale showed; $8.30 \%$ for level I, $17.70 \%$ for level II, $34.80 \%$ for level III, and $39.20 \%$ for level IV.

\section{Acknowledgements:}

The authors would like to extend their gratitude and thankfulness to all children and their families who participated in this study as well as the directors and workforces of hospitals and private physical therapy centers In El-Qalubia Governorate.

\section{Funding:}

This research received no specific grant from any funding agency in the public, commercial, or non-profit sectors.

\section{References}

1- GLIKLICH R., et al.: Registries for Evaluating Patient Outcomes: A User's Guide. Rockville, M.D.: Agency for Healthcare Research and Quality; AHRQ Publication, 1049, 2010.

2- SILVEIRA P., et al.: On the Design of Compliance Governance Dashboards for Effective Compliance and Audit Management. In: Dan A., Gittler F., Toumani F., editors. Service-Oriented Computing. ICSOC/ServiceWave 2009 Workshops. Springer Berlin; Heidelberg, 6275: 208-17, 2010.

3- CANS C., et al.: Cerebral palsy registries. In Seminars in Pediatric Neurology, 11 (1): 18-23, 2004.

4- KIRBY R. S., et al.: Prevalence and functioning of children with cerebral palsy in four areas of the United States in: A report from the Autism and Developmental Disabilities Monitoring Network. Res. Dev. Disabil., 32: 462-9 2011.

5- CHRISTENSEN D., et al.: Prevalence of cerebral palsy, co-occurring autism spectrum disorders, and motor func- 
tioning-Autism and Developmental Disabilities Monitoring Network, USA, 2008. Dev. Med. Child Neurol., 56: 5965, 2014.

6- REID S.M., et al.: Temporal trends in cerebral palsy by impairment severity and birth gestation. Dev. Med. Child Neurol., 58 (Suppl. 2), 25-35, 2016.

7- ZHANG J.Y., et al.: A population-based study of communication impairment in cerebral palsy. J. Child Neurol., 30: 277-84, 2015.

8- MEI C., et al.: Language outcomes of children with cerebral palsy aged 5 years and 6 years: A populationbased study. Dev. Med. Child Neurol., 58: 605-11, 2016.

9- LEVY S.E., et al.: Autism spectrum disorder and cooccurring developmental, psychiatric, and medical conditions among children in multiple populations of the United States. J. Dev. Behav. Pediatr., 31: 267-75, 2010.

10- PAKULA A.T., et al.: Cerebral palsy: Classification and epidemiology. Phys. Med. Rehabil. Clin. N. Am., 20: 42552, 2009.

11- DELOBEL-AYOUB M., et al.: Prevalence and characteristics of autism spectrum disorders in children with cerebral palsy. Dev. Med. Child Neurol., 59: 738-42, 2017.

12- ROSENBAUM P., et al.: A report: The definition and classification of cerebral palsy April. Dev. Med. Child Neurol., 109: 8-14, 2007.

13- ANDO N., et al.: Functional deterioration in adults with cerebral palsy. Clin. Rehabil., 14 (3): 300-6, 2000.

14- PALISANO R., et al.: Content validity of the expanded and revised gross motor function classification system. Dev. Med. Child. Neurol., 50: 744-50, 2008.

15- RUSSELL D., et al.: Gross Motor Function Measure (GMFM-66 \& GMFM-88) User's Manual. London: Mac Keith Press, 2013.

16- ELIAS SON A., et al.: The Manual Ability Classification System (MACS) for children with cerebral palsy: Scale development and evidence of validity and reliability Develpmental Medicine and Chil. Neurology, 48: 54954, 2006.

17- PENNINGTON L., et al.: Viking Speech Scale, 2010.

18- JOHNSON A.: Europe". Developmental Medicine and Child Neurology, 44 (9): 633-40, 2002.

19- LAISRAM N., et al.: Cerebral palsy-An Etiological Study. Indian Journal of Prdiatrics, 59: 723-801, 1992.

20- HAMDY N. EL-TALLAWY, et al.: Epidemiology of cerebral palsy in El-Kharga District-New Valley (Egypt), Pages, 406-11, 2011.

21- ABD EL-AZIEM F.H., et al.: Registry of Cerebral Palsy in Minia Governorate (Banny-Mazar), 2016.

22- DAG MOSTER, et al.: Cerebral Palsy Among Term and Postterm Births, 2010.

23- OSKOUI M., et al.: An update on the prevalence of cerebral palsy: A systematic review and meta-analysis. Dev. Med. Child Neurol., 55: 509-19, 2013.
24- JONAS H. ELLENBERG, et al.: Am. J. Dis. Child, 133: 1044-8, 1979.

25- PLATT M., et al.: Trends in cerebral palsy among infants of very low birthweight $(<1500 \mathrm{~g})$ or born prematurely ( $<32$ weeks) in 16 European centers: A database study. The Lancet, 369: 43-50, 2007.

26- CANS C., et al.: Cerebral palsy registries. Seminpediatrneurol., (1): 18-23, 2008.

27- ROSENBAUM P., et al.: A report: The definition and classification of cerebral palsy April. Dev. Med. Child. Neurol., 109: 8-14, 2007.

28- BLAIR E.: Epidemiology of the cerebral palsies. Orthop. Clin. North Am., 41: 441-55, 2010.

29- PARKINSON K., et al.: Pain in children with cerebral palsy: A cross-sectional multicenter European study. Acta Paediatr., 99: 1446-51, 2010.

30- STANLEY F., et al.: Cerebral palsies: Epidemiology and causal pathways. London: Mac Keith 1 st Ed., (151): 18 21, 2000.

31- BELONWU R.O., et al.: Cerebral palsy in Kano, Nigeriaa review. Niger. J. Med., 18: 186-9, 2009.

32- HIMMELMAN K., et al.: The changing panorama of cerebral palsy in Sweden X. Prevalence and origin in the birth-year period 1999-2002. Acta Paediatr early online access, 2010.

33- Cerbral Palsy Guide: http://www. Cerebralpalsyguide com/cerebral-palsy/coexisting-condtions/epilepsy Accessed in 15, May, 2018.

34- ASHWAL S., et al.: "Practice parameter: Diagnostic assessment of the child with cerebral palsy: Report of the Quality Standards Subcommittee of the American Academy of Neurology and the Practice Committee of the Child Neurology Society". Neurology, 62 (6): 851-63, 2004.

35- TONG-WAI R., et al.: A clinical and etiologic profile of spastic diplegia. Pediatric Neurology, 34 (3): 212-8, 2006.

36- NORMARK E., et al.: Cerebral palsy in Southern Sweden. I. Prevalence and clinical features. Acta Paediatr, 90: 1271-6, 2001

37- HOWARD J., et al.: Cerebral palsy in Victoria: Motor types, topography and gross motor function. J. Paediatr. Child Health, 41: 479-83, 2005.

38- EL-TALLAWY H.N., et al.: Epileptic and cognitive changes in children with cerebral palsy: An Egyptian study. Neuropsychiatr Dis. Treat., 10: 971-5, 2014.

39- MCHALE D., et al.: "A gene for ataxic cerebral palsy maps to chromosome 9p12-q12". European Journal of Human Genetics, 8 (4): 267-27, 2000.

40- BECKUNG E., et al.: The natural history of gross motor development in children with cerebral palsy aged 1 to 15 years. Dev. Med. Child. Neurol., 49: 751-6, 2007.

41- HIMMELMANN K., et al.: Gross and fine motor function and accompanying impairments in cerebral palsy. Dev. Med. Child Neurol., 48: 471-23, 2006. 
42- LÖWING K., et al.: Introduction of the gross motor functionclassification system in Venezuela-a modelfor knowledge dissemination. B.M.C. Pediatrics 15-111 Doi. 10.1186/s12887-015-0433-5, 2015.

43- HESHAM S. DARWESH, et al.: Physical Therapy Registry for Establishment of Cerebral Palsy in Imbaba North Giza. Med. J. Cairo Univ. Vol., 85, No., 2, March: 48792, 2017.
44- JAN M.: Cerebralpalsy: Comprehensive review and update Ann. Saudi. Med., 26: pp. 123-32, 2010.

45- NOVAK I., et al.: Clinical prognostic messages from a systematic review on cerebral palsy. Pediatrics, 30: 1285312,2012

46- SHEVELL M.I.: Cerebral palsy: Defining the problem. Semin. Pediatr. Neurol. Mar., 11 (1): 2-4, 2004.

\title{
تسجيل مرضى الشلل الدماغى بمحافظة القليوبية
}

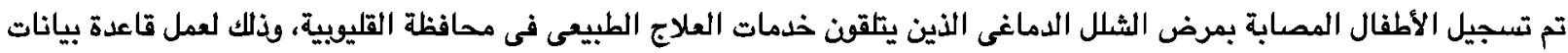

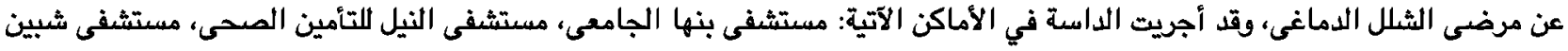

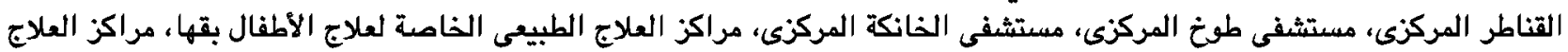

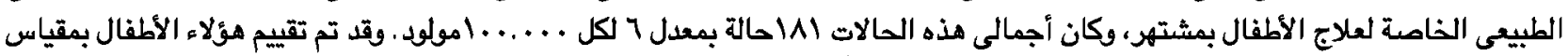

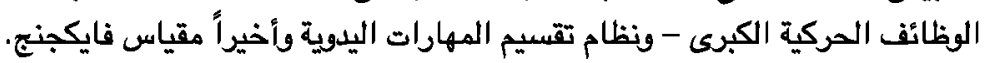

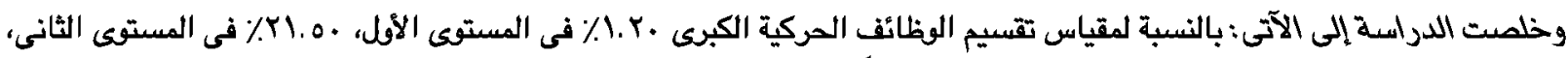

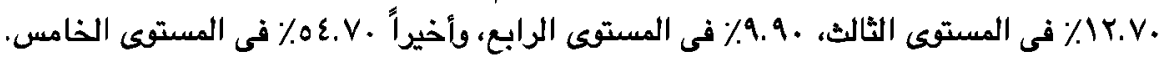

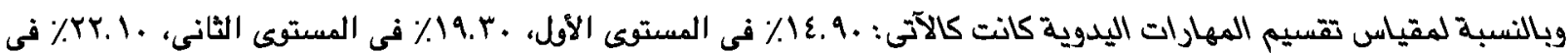

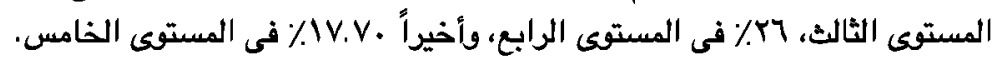

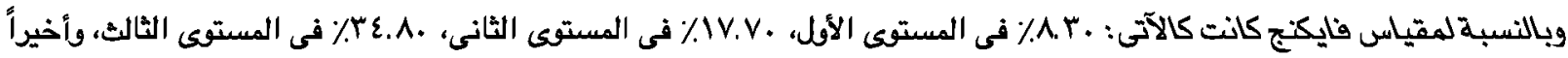

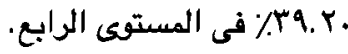

